\section{Outcomes of colpectomy for uterovaginal and posthysterectomy vault prolapse: A comparative study between normal and overweight women}

Pattaya Hengrasmee, Parit Wachasiddhisilpa, Chutimon Asumpinwong, Pichai Leerasiri

Urogynecology Unit, Department of Obstetrics and Gynecology, Faculty of Medicine, Siriraj Hospital, Mahidol University, Bangkok, Thailand

\section{Abstract}

The objective of the study is to compare success and perioperative outcomes of colpectomy for severe prolapse between normal and overweight patients. This is a retrospective cohort study of 95 non-sexually active women undergoing colpectomy for severe prolapse between July 2010 and December 2015. Vaginal hysterectomy was performed for those with uterovaginal prolapse. Prolapse stage and location were identified according to Pelvic Organ Prolapse Quantification (POP-Q) measurements. Demographic data and perioperative outcomes were recorded. Patients were categorized into normal-weight and overweight groups according to World Health Organization body mass index classification for adults. During postoperative visit, prolapse symptoms and POP-Q measurements were re-evaluated. Objective cure was defined as prolapse at or above hymen, while subjective cure determined as resolution of prolapse sensation. One-third was determined as overweight. Objective cure was $81.1 \%$, whereas subjective cure was $95.8 \%$. Overweight patients significantly demonstrated poorer perioperative outcomes including increased blood loss, more advanced stage prolapse, and lower success rates. In conclusion, colpectomy is an effective repair procedure for non-sexually active women with severe prolapse due to low perioperative morbidities and favorable surgical outcomes. However, special precaution is required when performing this procedure in overweight women.

\section{Introduction}

Pelvic organ prolapse (POP) is one of the major health problems affecting almost half of women over 50 years of age, with a lifetime prevalence of $30-50 \%{ }^{1}$ Apart from increasing age, other independent factors contributing to the development of POP have been identified including parity, vaginal delivery, size of born infant, race, and body mass index (BMI). ${ }^{2,3}$ Results from previous studies have confirmed that overweight and obesity are associated with POP incidence and progression, as well as anatomical and functional recurrence..$^{2,3}$ Having been quoted by many published literatures, a lifetime risk of POP surgery is estimated to be $12.6 \%$ by the age of 80 years, ${ }^{4}$ with a reoperation rate of $29 \% .{ }^{5}$ With aging population and escalating prevalence of overweight and obesity worldwide, these could have a tremendous impact on the management trends and operative outcomes of pelvic organ prolapse.

Although conservative management, such as pessary, is an effective method for treating prolapse, especially in obese patients who tend to have more surgical risks and perioperative complications, most patients are rather inclined towards more permanent solution. Current surgical approaches for POP repair procedures include abdominal, vaginal, laparoscopic, or combined technique. To select the most appropriate strategy, one should take into consideration the location and severity of prolapse, concurrent pelvic pathology, patient's preference, sexual activity, overall health status, and expected outcomes.

Colpocleisis or colpectomy is an obliterative vaginal procedure performed to treat POP by reducing the prolapsed viscera, closing a portion of vaginal canal, shortening the vaginal length and narrowing the genital hiatus. It is considered as an effective and economical procedure with good surgical outcomes, few adverse events (6.8$15 \%)$ and low recurrence rates, as well as high patient satisfaction scores. ${ }^{6-9}$ Colpectomy with concomitant vaginal hysterectomy may be more preferable procedures than colpectomy alone in healthy, elderly, obese patients with advanced stage prolapse who are no longer sexually active due to the advantages of: i) optimal exposure to cul de sac closure and cysto-rectocele repair, ii) removal of potential danger of a difficult-to-access uterus, iii) patient's preference of the most definitive method, and iv) avoidance of vaginal mesh repair and mesh complications. However, very few studies have examined the perioperative morbidities and the surgical outcomes of colpectomy and concomitant vaginal hysterectomy among overweight and obese patients. Therefore, the aim of this study are to compare the clinical outcomes of colpec-
Correspondence: Pattaya Hengrasmee, Urogynecology Unit, Department of Obstetrics and Gynecology, Faculty of Medicine, Siriraj Hospital, Mahidol University, 2 Prannok Road, Siriraj, Bangkoknoi, Bangkok 10700, Thailand. Tel.: 662.419.4782 - Fax: 662.419.4783

E-mail: phengras@yahoo.com

Key words: Pelvic organ prolapse; Colpectomy; Overweight women; Success rates; Perioperative outcomes.

Acknowledgments: all patient charts for review in this study were electronically provided by the Medical Statistics Unit, Faculty of Medicine, Siriraj Hospital. We also appreciate the help from the staff of Urogynecology Unit regarding patient data collection.

Contributions: $\mathrm{PH}$ : project development, data collection, data analysis, manuscript writing/editing; PW: project development, data collection; CA: data collection, data analysis; PL: project development; manuscript editing.

Conflict of interest: the authors declare no potential conflict of interest.

Funding: none.

Received for publication: 2 February 2018.

Revision received: 31 March 2018.

Accepted for publication: 21 March 2019

This work is licensed under a Creative Commons Attribution NonCommercial 4.0 License (CC BY-NC 4.0).

(C) Copyright P. Hengrasmee et al., 2019

Licensee PAGEPress, Italy

Urogynaecologia 2019; 31:213

doi:10.4081/uij.2019.213

tomy with or without concomitant vaginal hysterectomy for the treatment of advanced stage POP between normal and overweight patients in terms of success rate, recurrence rate, functional outcomes, and perioperative adverse events.

\section{Materials and Methods}

This is a retrospective cohort study of non-sexually active women undergoing colpectomy with or without concomitant vaginal hysterectomy for advanced stage uterovaginal prolapse and posthysterectomy vaginal vault prolapse at a university-affiliated tertiary medical center between July 2010 and December 2015. With the Institutional Review Board's ethical 
approval (project number 304/2559 EC4), the patient medical records were retrospectively reviewed. Cases with incomplete medical data were excluded.

Following clinical symptom assessment, the stage and the location of POP were identified according to the Pelvic Organ Prolapse Quantification (POP-Q) system. ${ }^{10}$ Preoperative urodynamic study was carried out when indicated. Colpectomy was performed in sexually inactive patients who refused or failed to use a vaginal pessary. Traditional vaginal hysterectomy was implemented in all patients diagnosed with uterovaginal prolapse having normal preoperative cervical cytology. Colpectomy and all other concurrent procedures were managed by 2 urogynecologists. Concomitant anti-incontinence surgery was undertaken based on patients' preoperative symptoms and/or urodynamic findings.

Colpectomy was achieved by making a landmark circumferential incision on the vagina approximately $2 \mathrm{~cm}$ above the hymen, followed by a midline incision on both anterior and posterior vaginal walls. With sharp and blunt lateral dissection, vaginal epithelium was 360-degree separated from the underlying pubocervical and rectovaginal fascia. The dissection was continued until approaching pubic rami anteriorly and levator hiatus posteriorly. The excess vaginal epithelium was then excised. Peritonealization was performed if applicable, followed by the plication of perivesical, apical, and perirectal fascia with 2 to 3 consecutive delayed absorbable purse-string sutures, and closure of vaginal incision. The posterior colporrhaphy, with or without perineorrhaphy, was also carried out when required. An indwelling catheter was inserted at the end of the operation and removed on the postoperative day 2 after passing the trial of void. If the post-void residual urine exceeded $150 \mathrm{~mL}$, another trial of void was repeated in the office approximately 1 week afterwards.

Information regarding patients' demographic data, preoperative assessment, perioperative complications and operative outcomes were recorded. For data analysis, patients were categorized according to their BMI into normal-weight and overweight groups. With regard to World Health Organization BMI classification for adults, the normal weight is defined as a BMI between 18.50 and $24.99 \mathrm{~kg} / \mathrm{m}^{2}$ and the overweight is defined as a BMI ranging from 25.00 to $29.99 \mathrm{~kg} / \mathrm{m}^{2}$. Postoperative follow-up was scheduled at 1 month, 3 months, 6 months, 1 year, and annually thereafter. At each follow-up visit, reassessment of symptoms and POP-Q measurements was undertaken. Success rates in terms of objective and subjective cure were considered as our primary outcomes. As reported by previous epidemiological studies, POP symptoms manifested by patients are strongly associated with prolapse beyond the level of hymen. Therefore, the objective cure was defined according to the NICHD Pelvic Floor Disorders Network recommendations ${ }^{11}$ as prolapse (points Aa, Ap, and C) at or above hymen, and the subjective cure determined as resolution of prolapse sensation at the last follow-up visit. Apart from treatment success, our study also investigated for secondary outcomes which included changes in urinary and defecatory symptoms, as well as perioperative morbidities.

\section{Statistical analysis}

All statistical analyses were performed using the Statistical Packages for the Social Sciences version 18 for Windows (PASW statistic18). Continuous variables were presented as mean \pm standard deviation whereas categorical data were expressed in terms of number and percentage with $95 \%$ confidence intervals. The differences in POP-Q measurements prior to and after surgery were determined using Paired-Samples $\mathrm{T}$ test, whereas Independent-Samples $\mathrm{T}$ test and Pearson Chi-square test were used to demonstrate the difference between normalweight and overweight groups. P-value of less than 0.05 was considered as an indicator for statistical significance.

\section{Results}

A total of 95 non-sexually active women underwent colpectomy with or without concomitant vaginal hysterectomy for advanced stage uterovaginal prolapse and posthysterectomy vaginal vault prolapse during the study period. All women were menopause and had no significant medical risks. The mean age was $70.8 \pm 8.1$ years. One-third (34 out of $95 ; 35.79 \%$ ) was determined as overweight, whereas the rest represented the normal-weight category. The mean BMI of patients in the overweight group was significantly higher than the normal-weight group $\left(27.45 \pm 1.76 \mathrm{~kg} / \mathrm{m}^{2}\right.$ vs $\left.22.03 \pm 2.26 \mathrm{~kg} / \mathrm{m}^{2} ; \mathrm{P}<0.001\right)$. The mean age, mean parity, and the rate of previous hysterectomy and other reconstructive procedures were similar for both groups as displayed in Table 1.

For preoperative assessment, there were no significant differences between the two groups in terms of clinical presentations including prolapse, urinary, and defecatory symptoms, with feeling of a bulge being the most common complaint in all patients. Approximately 97\% (92 out of 95) of the patients were determined as having advanced stage POP. Only a few were diagnosed with stage II prolapse. The identical proportion was distributed in both normal and overweight groups. Preoperative POP locations and POP-Q measurements were also comparable for both groups. Finally,

Table 1. Patient characteristics.

\begin{tabular}{|c|c|c|c|c|}
\hline & $\begin{array}{l}\text { Overall } \\
(n=95)\end{array}$ & $\begin{array}{l}\text { Normal weight } \\
(\mathrm{n}=61)\end{array}$ & $\begin{array}{l}\text { Overweight } \\
(n=34)\end{array}$ & P-value \\
\hline Age (y) & $70.8 \pm 8.1$ & $71.0 \pm 8.5$ & $70.6 \pm 7.5$ & 0.822 \\
\hline Parity & $4.1 \pm 2.4$ & $4.1 \pm 2.5$ & $4.0 \pm 2.3$ & 0.758 \\
\hline BMI $\left(\mathrm{kg} / \mathrm{m}^{2}\right)$ & $24.15 \pm 3.37$ & $22.03 \pm 2.26$ & $27.45 \pm 1.76$ & $<0.001$ \\
\hline $\begin{array}{l}\text { Past hysterectomy } \\
\text { Abdominal } \\
\text { Vaginal } \\
\end{array}$ & $\begin{array}{l}17(17.9) \\
7(7.4)\end{array}$ & $\begin{array}{l}10(16.4) \\
3(4.9)\end{array}$ & $\begin{array}{l}7(20.6) \\
4(11.8) \\
\end{array}$ & $\begin{array}{l}0.609 \\
0.221\end{array}$ \\
\hline $\begin{array}{l}\text { Past native tissue repair } \\
\text { Anterior repair } \\
\text { Posterior repair } \\
\text { US suspension } \\
\text { Sacrospinous fixation } \\
\end{array}$ & $\begin{array}{l}8(8.4) \\
8(8.4) \\
4(4.2) \\
1(1.1)\end{array}$ & $\begin{array}{l}3(4.9) \\
3(4.9) \\
2(3.3) \\
0(0.0)\end{array}$ & $\begin{array}{l}5(14.7) \\
5(14.7) \\
2(5.9) \\
1(2.9) \\
\end{array}$ & $\begin{array}{l}0.100 \\
0.100 \\
0.545 \\
0.178\end{array}$ \\
\hline
\end{tabular}

Data are presented as mean \pm standard deviation (SD) or number (\%). 
among 85 patients $(89.5 \%)$ undergoing preoperative urodynamic studies, results from the normal-weight group seemed to correspond with those of the overweight group (Table 2).

Colpectomy and concomitant vaginal hysterectomy were carried out in all patients with uterovaginal prolapse (71 out of $95 ; 74.7 \%$ ), whereas colpectomy alone was undertaken in those diagnosed with posthysterectomy vaginal vault prolapse. Concerning the rate of vaginal hysterectomy, no statistically significant difference was found between normal and overweight groups $(78.7 \%$ vs $67.6 \%$; $\mathrm{P}=0.235)$. Other concurrent procedures, such as posterior colporrhaphy $(9.5 \%)$, perineorrhaphy (3.2\%) and midurethral sling (28.4\%), were additionally performed only when indicated. Again, no significant difference was demonstrated for each procedure when compared between the two groups (Table 3).

The average operative time for all completed procedures was $65.61 \pm 32.64$ minutes (range 30-165 minutes) and the mean blood loss being $118.76 \pm 110.53 \mathrm{ml}$ (range 15-600 $\mathrm{ml}$ ). For the mean operative time, the results were analogous for both groups $(65.03 \pm 34.68$ vs $66.62 \pm 29.22 ; \mathrm{P}=0.823)$. On the other hand, significantly larger amount of blood loss was detected in the overweight group as opposed to the normal- weight counterpart $(153.68 \pm 146.49 \mathrm{ml} \mathrm{vs}$ $98.64 \pm 77.74 \mathrm{ml} ; \mathrm{P}=0.020)$. Moreover, when considered in terms of massive hemorrhage, two patients in the overweight group were reported to have intraoperative blood loss exceeding $500 \mathrm{ml}$, for which no blood transfusion was required. Despite this, no statistically significant difference was observed when compared between the two groups ( $0 \%$ vs $5.9 \% ; \mathrm{P}=0.056)$. Apart from massive bleeding, no other serious intraoperative complications were documented (Table 3 ).

Regarding postoperative adverse events such as urinary tract infection, wound complication, voiding difficulty, urge and stress incontinence, there were no considerable differences when compared between the normal-weight and the overweight groups. De novo stress incontinence was the most prevalent postoperative adverse event found in 16 out of 95 patients (16.8\%). Nevertheless, none required subsequent anti-incontinence surgery and were successfully managed with conservative treatment. Reports on histopathology also showed similar results for both groups. Of seventyone hysterectomy specimens, only 46 $(64.8 \%)$ were confirmed to have some pathology. Among these, no malignancy was identified. Cervicitis was the dominant pathology discovered in 20 patients, whereas cervical dysplasia was detected in only 4. Other pathology included cervical polyp, leiomyoma, adenomyosis and endometrial polyp (Table 3). All patients returned for one-month postoperative visit; however, 9 $(9.5 \%)$ were lost to follow-up thereafter. Overall, the mean follow-up time was $23.3 \pm 17.6$ months. Patients in the overweight group had significantly longer follow-up period than the normal weight group (29.9 \pm 17.3 months vs $19.6 \pm 16.7$ months; $\mathrm{P}=0.006$ ) (Table 5). Substantial improvement in clinical symptoms and POP-Q measurements was generally observed from early postoperative period up to 5 years in both groups. Nevertheless, those who were overweight significantly demonstrated poorer surgical outcomes with regard to POP-Q measurements and postoperative POP stage when compared to the normalweight individuals (Tables 3 and 4). Furthermore, they tended, though insignificantly, to continue having bothersome bulge and overactive bladder symptoms after surgery $(5.9 \%$ vs $0.0 \% ; \mathrm{P}=0.056$ and $32.4 \%$ vs $16.4 \% ; \mathrm{P}=0.072$, respectively) (Table 3 ).

The overall success rate of colpectomy procedure with or without concomitant vaginal hysterectomy was $76.8 \%$ (73 out of $95)$, which was further differentiated into the objective cure of $81.1 \%$ (77 out of 95 ) and the subjective cure of $95.8 \%$ (91 out of 95). Of 22 patients with recurrent prolapse, only 4 in the overweight group experienced symptomatic bulge. When compared

Table 2. Preoperative clinical assessment.

\begin{tabular}{|c|c|c|c|c|}
\hline & $\begin{array}{l}\text { Overall } \\
(\mathrm{n}=95)\end{array}$ & $\begin{array}{l}\text { Normal weight } \\
(\mathrm{n}=61)\end{array}$ & $\begin{array}{l}\text { Overweight } \\
(\mathrm{n}=34)\end{array}$ & P-value \\
\hline $\begin{array}{l}\text { Prolapse symptom } \\
\text { Bulging } \\
\text { Dragging } \\
\text { Backache }\end{array}$ & $\begin{array}{l}95(100.0) \\
70(73.7) \\
9(9.5)\end{array}$ & $\begin{array}{l}61(100.0) \\
44(72.1) \\
4(6.6)\end{array}$ & $\begin{array}{l}34(100.0) \\
26(76.5) \\
5(14.7)\end{array}$ & $\begin{array}{l}\text { NA } \\
0.645 \\
0.194\end{array}$ \\
\hline $\begin{array}{l}\text { Urinary symptom } \\
\text { Voiding difficulty } \\
\text { Stress incontinence } \\
\text { Overactive bladder } \\
\text { Defecatory symptom } \\
\end{array}$ & $\begin{array}{l}83(87.4) \\
50(52.6) \\
78(82.1)\end{array}$ & $\begin{array}{l}52(85.2) \\
30(49.2) \\
51(83.6)\end{array}$ & $\begin{array}{l}31(91.2) \\
20(58.8) \\
27(79.4)\end{array}$ & $\begin{array}{l}0.404 \\
0.367 \\
0.609\end{array}$ \\
\hline $\begin{array}{l}\text { Incomplete evacuation } \\
\text { Straining } \\
\text { Digitation } \\
\text { Constipation }\end{array}$ & $\begin{array}{l}40(42.1) \\
62(65.3) \\
28(29.5) \\
40(42.1)\end{array}$ & $\begin{array}{l}27(44.3) \\
42(68.9) \\
19(31.1) \\
27(44.3)\end{array}$ & $\begin{array}{l}13(38.2) \\
20(58.8) \\
9(26.5) \\
13(38.2)\end{array}$ & $\begin{array}{l}0.568 \\
0.325 \\
0.632 \\
0.568\end{array}$ \\
\hline $\begin{array}{l}\text { Urodynamic diagnoses } \\
\text { USI } \\
\text { DO } \\
\text { BOO }\end{array}$ & $\begin{array}{l}22(23.2) \\
12(12.6) \\
20(21.1)\end{array}$ & $\begin{array}{l}15(24.6) \\
8(13.1) \\
12(19.7)\end{array}$ & $\begin{array}{l}7(20.6) \\
4(11.8) \\
8(23.5)\end{array}$ & $\begin{array}{l}0.658 \\
0.849 \\
0.658\end{array}$ \\
\hline $\begin{array}{l}\text { POP stage } \\
\text { II } \\
\text { III } \\
\text { IV }\end{array}$ & $\begin{array}{l}3(3.2) \\
29(30.5) \\
63(66.3)\end{array}$ & $\begin{array}{l}2(3.3) \\
19(31.1) \\
40(65.6)\end{array}$ & $\begin{array}{l}1(2.9) \\
10(29.4) \\
23(67.6)\end{array}$ & 0.978 \\
\hline $\begin{array}{l}\text { POP location } \\
\text { Apical } \\
\text { Anterior } \pm \text { apical } \\
\text { Posterior } \pm \text { apical } \\
\text { All compartment }\end{array}$ & $\begin{array}{l}2(2.1) \\
8(8.4) \\
1(1.1) \\
84(88.4)\end{array}$ & $\begin{array}{l}2(3.3) \\
6(9.8) \\
1(1.6) \\
52(85.2)\end{array}$ & $\begin{array}{l}0(0.0) \\
2(5.9) \\
0(0.0) \\
32(94.1)\end{array}$ & 0.518 \\
\hline
\end{tabular}


regarding the rates of recurrence, the overweight patients had significantly higher objective and subjective recurrent rates than the normal-weight group $(32.4 \%$ vs $11.5 \%$; $\mathrm{P}=0.013$ and $11.8 \%$ vs $0.0 \% ; \mathrm{P}=0.006$, respectively) (Table 5). Using the hymeneal ring as the cut-off point to define POP recurrence, $11(11.6 \%)$ patients were found to have recurrent stage II prolapse while 7 (7.3\%) were diagnosed with recurrent stage III prolapse. Among these, two-thirds (11 out of 18) were recognized as being overweight $(\mathrm{P}=0.035)$. For the site of recurrence, $12(12.6 \%)$ occurred in the anterior vaginal compartment, $10(9.5 \%)$ appeared in the posterior vaginal compartment, and $11(11.6 \%)$ recurred in the apex. When separately evaluated according to different locations of recurrent prolapse, patients in the overweight group significantly outnumbered those in the normal-weight group in

Table 3. Operative outcomes.

\begin{tabular}{|c|c|c|c|c|}
\hline & $\begin{array}{l}\text { Overall } \\
(n=95)\end{array}$ & $\begin{array}{l}\text { Normal weight } \\
(\mathrm{n}=61)\end{array}$ & $\begin{array}{l}\text { Overweight } \\
(n=34)\end{array}$ & P-value \\
\hline Estimated blood loss (ml) & $118.76 \pm 110.53$ & $98.64 \pm 77.74$ & $153.68 \pm 146.49$ & 0.020 \\
\hline Operative time (min) & $65.61 \pm 32.64$ & $65.03 \pm 34.68$ & $66.62 \pm 29.22$ & 0.823 \\
\hline V-hysterectomy & $71(74.7)$ & $48(78.7)$ & $23(67.6)$ & 0.235 \\
\hline $\begin{array}{l}\text { Concomitant procedures } \\
\text { Posterior repair } \\
\text { Perineorrhaphy } \\
\text { Midurethral sling } \\
\text { Massive bleeding (>500 ml) }\end{array}$ & $\begin{array}{l}9(9.5) \\
3(3.2) \\
27(28.4) \\
2(2.1)\end{array}$ & $\begin{array}{l}5(8.2) \\
1(1.6) \\
17(27.9) \\
0(0.0)\end{array}$ & $\begin{array}{l}4(11.8) \\
2(5.9) \\
10(29.4) \\
2(5.9)\end{array}$ & $\begin{array}{l}0.569 \\
0.257 \\
0.873 \\
0.056\end{array}$ \\
\hline $\begin{array}{l}\text { Postoperative complication } \\
\text { UTI } \\
\text { Wound infection } \\
\text { Voiding difficulty } \\
\text { De novo urge } \\
\text { De novo SUI }\end{array}$ & $\begin{array}{l}2(2.1) \\
1(1.1) \\
3(3.2) \\
2(2.1) \\
16(16.8)\end{array}$ & $\begin{array}{l}1(1.6) \\
1(1.6) \\
2(3.3) \\
2(3.3) \\
11(18.0)\end{array}$ & $\begin{array}{l}1(2.9) \\
0(0.0) \\
1(2.9) \\
0(0.0) \\
5(14.7)\end{array}$ & $\begin{array}{l}0.672 \\
0.453 \\
0.928 \\
0.286 \\
0.678\end{array}$ \\
\hline $\begin{array}{l}\text { Pathology } \\
\text { Cervicitis } \\
\text { Endocervical polyp } \\
\text { Cervical dysplasia } \\
\text { Leiomyoma } \\
\text { Adenomyosis } \\
\text { Endometrial polyp } \\
\end{array}$ & $\begin{array}{l}19(20.0) \\
5(5.3) \\
4(4.2) \\
16(16.8) \\
14(14.7) \\
9(9.5)\end{array}$ & $\begin{array}{l}14(23.0) \\
3(4.9) \\
2(3.3) \\
13(21.3) \\
9(14.8) \\
4(6.6)\end{array}$ & $\begin{array}{l}5(14.7) \\
2(5.9) \\
2(5.9) \\
3(8.8) \\
5(14.7) \\
5(14.7)\end{array}$ & $\begin{array}{l}0.335 \\
0.840 \\
0.545 \\
0.119 \\
0.995 \\
0.194\end{array}$ \\
\hline $\begin{array}{l}\text { Postoperative symptoms } \\
\text { Bulging symptom } \\
\text { Voiding difficulty } \\
\text { SUI } \\
\text { OAB } \\
\text { Defecatory symptom }\end{array}$ & $\begin{array}{l}2(2.1) \\
2(2.1) \\
4(4.2) \\
21(22.1) \\
3(3.2)\end{array}$ & $\begin{array}{l}0(0.0) \\
1(1.6) \\
2(3.3) \\
10(16.4) \\
2(3.3)\end{array}$ & $\begin{array}{l}2(5.9) \\
1(2.9) \\
2(5.9) \\
11(32.4) \\
1(2.9)\end{array}$ & $\begin{array}{l}0.056 \\
0.672 \\
0.545 \\
0.072 \\
0.928\end{array}$ \\
\hline $\begin{array}{l}\text { Postoperative POP stage } \\
0 \text { or I } \\
\text { II } \\
\text { III or IV }\end{array}$ & $\begin{array}{l}29(30.5) \\
60(63.2) \\
6(6.3)\end{array}$ & $\begin{array}{l}24(39.3) \\
35(57.4) \\
2(3.3)\end{array}$ & $\begin{array}{l}5(14.7) \\
25(73.5) \\
4(11.8)\end{array}$ & 0.021 \\
\hline
\end{tabular}

Data are presented as mean \pm standard deviation (SD) or number (\%). UTI, urinary tract infection; SUI, stress urinary incontinence; OAB, overactive bladder.

Table 4. Pre- and post-operative pelvic organ prolapse quantification measurements.

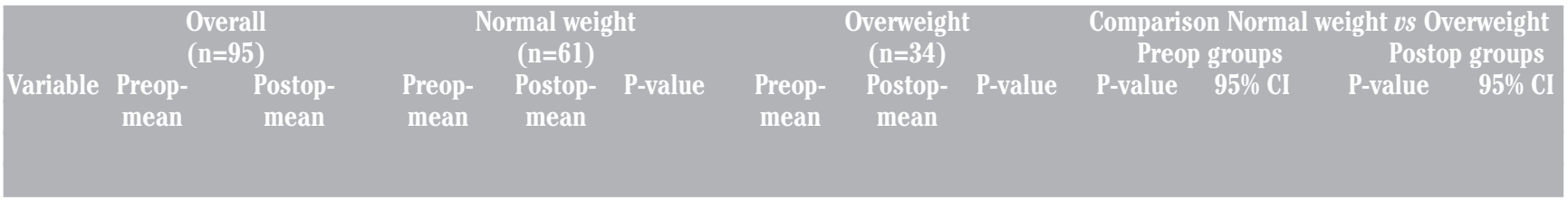

\begin{tabular}{lcccccccccccc} 
Aa & $+2.45 \pm 1.28$ & $-0.71 \pm 1.23$ & $+2.36 \pm 1.40$ & $-1.05 \pm 1.04$ & $<0.001$ & $+2.62 \pm 1.02$ & $-0.15 \pm 1.31$ & $<0.001$ & 0.350 & -0.80 to 0.29 & 0.001 & -1.41 to -0.41 \\
Ap & $+1.49 \pm 1.92$ & $-0.80 \pm 1.22$ & $+1.33 \pm 2.01$ & $-1.02 \pm 1.13$ & $<0.001$ & $+1.79 \pm 1.74$ & $-0.44 \pm 1.28$ & $<0.001$ & 0.258 & -1.28 to 0.35 & 0.029 & -1.09 to -0.06 \\
\hline C & $+5.12 \pm 2.67$ & $-1.15 \pm 1.59$ & $+4.80 \pm 2.94$ & $-1.44 \pm 1.23$ & $<0.001$ & $+5.68 \pm 2.03$ & $-0.68 \pm 1.97$ & $<0.001$ & 0.128 & -2.00 to 0.26 & 0.027 & -1.43 to -0.09 \\
gh & $4.49 \pm 1.36$ & $3.38 \pm 1.06$ & $4.38 \pm 1.39$ & $3.15 \pm 1.01$ & $<0.001$ & $4.71 \pm 1.29$ & $3.76 \pm 1.05$ & $<0.001$ & 0.261 & -0.91 to 0.25 & 0.007 & -1.06 to -0.18 \\
\hline pb & $2.85 \pm 0.62$ & $3.24 \pm 0.83$ & $2.77 \pm 0.59$ & $3.02 \pm 0.65$ & 0.028 & $3.00 \pm 0.65$ & $3.59 \pm 0.96$ & 0.007 & 0.083 & -0.49 to 0.03 & 0.001 & -0.91 to -0.23 \\
Ba & $+4.62 \pm 2.11$ & & $+4.44 \pm 2.34$ & & & $+4.94 \pm 1.61$ & & & 0.272 & -1.39 to 0.40 & \\
Bp & $+3.68 \pm 2.72$ & & $+3.46 \pm 2.80$ & & & $+4.09 \pm 2.55$ & & & 0.282 & -1.78 to 0.53 & \\
TVL & $7.28 \pm 1.42$ & & $7.13 \pm 1.37$ & & & $7.56 \pm 1.48$ & & & 0.160 & -1.03 to 0.17 &
\end{tabular}

Data are presented as mean \pm standard deviation (SD) or number (\%).TVL, total vaginal length. 
every compartment (Table 5). Almost all patients with POP recurrence were conservatively managed with success, except for one patient with stage II all-compartment prolapse who subsequently underwent anterior vaginal mesh repair and posterior colporrhaphy procedures.

\section{Discussion}

Although the mean age of the patients was rather elevated $(70.8 \pm 8.1$ years), there was no significant difference between the two groups $(\mathrm{P}=0.822)$. Preoperative urodynamic study had failed to confirm the presence of stress incontinence in 5 patients (22 out of 27) whose clinical examination revealed significantly positive cough stress test. As a result, concomitant midurethral sling was required among 27 patients (28.4\%) to relieve their bothersome symptom. Sixteen out of 95 patients $(16.8 \%)$ experienced postoperative de novo stress incontinence. Nevertheless, none required subsequent anti-incontinence surgery and were successfully managed with conservative treatment, meaning that prophylactic anti-incontinence procedure might not be useful.

Colpectomy, with or without concomitant vaginal hysterectomy, has been considered as an effective obliterative procedure for women with advanced stage POP, having favorable surgical outcomes and low perioperative complications. With few literatures addressing perioperative outcomes of this procedure in overweight and obese patients, our study aimed to determine whether BMI has any impact on perioperative morbidities and treatment success. In terms of intraoperative complications, overweight or elevated BMI between 25.00 and $29.99 \mathrm{~kg} / \mathrm{m}^{2}$ was significantly associated with larger volume of blood loss. The result was rather different from the findings of most previous studies in which major adverse events were uncommon. ${ }^{12,13}$ The rationale for this is that overweight patients tend to have spacious vaginal surface area for which the dissection to separate the epithelium from the underlying fascia can become more difficult and extensive, leading to increased risk of bleeding. Furthermore, epidemiological evidence has confirmed that excess body weight is an important source of unopposed estrogen by means of aromatization of androgens in adipose tissue. ${ }^{14}$ Estrogen subsequently exerts several effects on endothelial cells and vascular smooth muscle through endothelialderived factors resulting in vasodilation and increased blood flow to the area of dissection. ${ }^{15}$ Bleeding complication and prolonged operative time were often found to be correlated with concomitant vaginal hysterectomy in previous trials. ${ }^{13}$ However, our study failed to demonstrate any negative effect of vaginal hysterectomy on perioperative outcomes in both normal-weight and overweight patients

Overweight patients were determined to have significantly higher recurrent rates, both objective and subjective, when compared with the normal-weight counterparts. Although there were no existing data regarding surgical outcomes of colpectomy in overweight and obese patients, similar findings were reported in several comparative studies evaluating outcomes of anterior colporrhaphy and vaginal uterosacral ligament suspension. ${ }^{16,17}$ The mechanism of POP recurrence among overweight and obese individuals is probably the chronic increase in intra-abdominal pressure that causes subsequent weakening of pelvic floor muscles and fascia. More skillful and meticulous surgical techniques as well as weight reduction may be helpful in improving operative outcomes.

When further examining in terms of success rates, the subjective cure $(95.8 \%)$ was substantially greater than the objective cure $(81.1 \%)$ and the overall success rate $(76.8 \%)$. Of 18 patients who were objectively found to have a protruding lump beyond hymen during the last follow-up visit, none complained of bothersome bulge symptom. This mild to moderate degree of recurrent POP might be adequately perceived by the patients as a relative cure when compared to the previously experienced advanced stage prolapse. Also, this trivial bulge could remain asymptomatic and unnoticeable as long as no strenuous daily activities were involved. Four out of fifteen patients in the overweight group developed both objective and subjective POP recurrence while seven in the normalweight group were symptom-free. The result corresponded with those from earlier studies which confirmed the influence of high BMI on the evolvement of symptomatic bulge. ${ }^{18,19}$ Although the association between weight reduction and improvement of prolapse sensation seems uncertain, several trials on bariatric surgeries for weight loss have reported better quality of life, as far as POP symptoms are concerned..$^{20}$ Thus, weight reduction should be continuously encouraged among overweight and obese patients prior to and after prolapse surgery to lessen the negative impact of high BMI on postoperative POP symptoms.

Although our study has demonstrated

Table 5. Postoperative follow-up and pelvic organ prolapse recurrence.

\begin{tabular}{|c|c|c|c|c|}
\hline & $\begin{array}{l}\text { Overall } \\
(\mathrm{n}=95)\end{array}$ & $\begin{array}{l}\text { Normal weight } \\
(\mathrm{n}=61)\end{array}$ & $\begin{array}{l}\text { Overweight } \\
(\mathrm{n}=34)\end{array}$ & P-value \\
\hline $\begin{array}{l}\text { Follow-up time } \\
\text { Mean F/U (days) }\end{array}$ & $699.38 \pm 526.82$ & $589.26 \pm 501.46$ & $896.94 \pm 520.31$ & 0.006 \\
\hline $\begin{array}{l}\text { Recurrence time } \\
\text { Mean recurrence (days) }\end{array}$ & $556.89 \pm 504.75$ & $525.29 \pm 401.62$ & $577.00 \pm 578.96$ & 0.840 \\
\hline $\begin{array}{l}\text { Type of recurrence } \\
\text { Objective } \\
\text { Subjective }\end{array}$ & $\begin{array}{l}18(18.9) \\
4(4.2)\end{array}$ & $\begin{array}{l}7(11.5) \\
0(0.0)\end{array}$ & $\begin{array}{l}11(32.4) \\
4(11.8)\end{array}$ & $\begin{array}{l}0.013 \\
0.006\end{array}$ \\
\hline $\begin{array}{l}\text { Stage of recurrence } \\
\text { No recurrence } \\
\text { II } \\
\text { III }\end{array}$ & $\begin{array}{l}77(81.1) \\
11(11.6) \\
7(7.3)\end{array}$ & $\begin{array}{l}54(88.5) \\
5(8.2) \\
2(3.3)\end{array}$ & $\begin{array}{l}23(67.6) \\
6(17.6) \\
5(14.7)\end{array}$ & 0.035 \\
\hline $\begin{array}{l}\text { Location of recurrence } \\
\text { Anterior } \\
\text { Posterior } \\
\text { Apical } \\
\text { All compartment } \\
\end{array}$ & $\begin{array}{l}12(12.6) \\
10(10.5) \\
11(11.6) \\
5(5.3)\end{array}$ & $\begin{array}{l}3(4.9) \\
3(4.9) \\
3(4.9) \\
0(0.0)\end{array}$ & $\begin{array}{l}9(26.5) \\
7(20.6) \\
8(23.5) \\
5(14.7) \\
\end{array}$ & $\begin{array}{l}0.002 \\
0.017 \\
0.007 \\
0.002\end{array}$ \\
\hline
\end{tabular}

Data are presented as mean + standard deviation (SD) or number (\%). 
outstanding information which can be useful and practical for the management of advanced stage POP in healthy, elderly, non-sexually active, obese patients, there are still unavoidable limitations including the retrospective nature of the study, the absence of randomization, the difference in surgical techniques, and the possibility of assessment bias. Furthermore, patients in the overweight group had significantly longer follow-up period than the normal weight group $(29.9 \pm 17.3$ months $v s$ $19.6 \pm 16.7$ months; $\mathrm{P}=0.006$ ). This could influence the observed clinical outcomes in the two groups.

\section{Conclusions}

Colpectomy, with or without concomitant vaginal hysterectomy, is an effective and safe procedure for healthy, elderly, nonsexually active women with advanced stage prolapse due to low perioperative morbidities and favorable surgical outcomes. However, special precaution is required when performing this procedure in an overweight or obese woman. Careful and meticulous dissection is mandatory in order to avoid bleeding complication. Thorough and intensive counseling with regard to intraoperative risks and the risk of recurrence is also essential. Finally, pre- and post-operative weight reduction should be sufficiently encouraged among overweight and obese women to help improve perioperative outcomes.

\section{References}

1. Subak LL, Waetjen LE, Van van den Eaden S, et al. Cost of pelvic organ prolapse surgery in the United States. Obstet Gynecol 2001;98:646-51.

2. Hendrix SL, Clark A, Nygaard I, et al.
Pelvic organ prolapse in the Women's Health Initiative: gravity and gravidity. Am J Obstet Gynecol 2002;186:1160-6.

3. Kudish BI, Iglesia CB, Sokol RJ, et al. Effect of weight change on the natural history of pelvic organ prolapse. Obstet Gynecol 2009;113:81-7.

4. Wu JM, Matthews CA, Conover MM, et al. Lifetime risk of stress urinary incontinence or pelvic organ prolapse surgery. Obstet Gynecol 2014;123: 1201-6.

5. Olsen AL, Smith VJ, Bergstrom JO, et al. Epidemiology of surgically managed pelvic organ prolapse and urinary incontinence. Obstet Gynecol 1997;89: 501-6.

6. Koski ME, Chow D, Bedestani A, et al. Colpocleisis for advanced pelvic organ prolapse. Urology 2012;80:542-6.

7. von Pechmann WS, Mutone M, Fyffe J, Hale DS. Total colpocleisis with high levator plication for the treatment of advanced pelvic organ prolapse. Am J Obstet Gynecol 2003;189:121-6.

8. Hullfish KL, Bovbjerg VE, Steers WD. Colpocleisis for pelvic organ prolapse: patient goals, quality of life, and satisfaction. Obstet Gynecol 2007;110:3415.

9. Mueller MG, Ellimootil C, Abernethy $\mathrm{MG}$, et al. Colpocleisis: a safe, minimally invasive option for pelvic organ prolapse. Female Pelvic Med Reconstr Surg 2015;21:30-3.

10. Haylen BT, Maher CF, Barber MD, et al. An International Urogynecological Association (IUGA)/International Continence Society (ICS) joint report on the terminology for female pelvic organ prolapse (POP). Int Urogynecol J 2016;27:655-84.

11. Barber MD, Brubaker L, Nygaard I, et al. Defining success after surgery for pelvic organ prolapse. Obstet Gynecol 2009;114:600-9.

12. Krissi H, Aviram A, Ram E, et al.
Colpocleisis surgery in women over 80 years old with severe triple compartment pelvic organ prolapse. Eur J Obstet Gynecol Reprod Biol 2015;195:206-9.

13. Hill AJ, Walters MD, Unger CA. Perioperative adverse events associated with colpocleisis for uterovaginal and posthysterectomy vaginal vault prolapse. Am J Obstet Gynecol 2016;214:501.e1-6.

14. Kaaks R, Lukanova A, Kurzer MS Obesity, endogenous hormones and endometrial cancer risk: A synthetic review. Cancer Epidemiol Biomarkers Prev 2002;11:1531-43.

15. Tolbert T, Oparil S. Cardiovascular effects of estrogen. Am J Hypertens 2001;14:186S-93S.

16. Kawasaki A, Corey EG, Laskey RA, et al. Obesity as a risk for the recurrence of anterior vaginal wall prolapse after anterior colporrhaphy. J Reprod Med 2013;58:195-9.

17. Edenfield AL, Amundsen CL, Weidner $\mathrm{AC}$, et al. Vaginal prolapse recurrence after uterosacral ligament suspension in normal-weight compared with overweight and obese women. Obstet Gynecol 2013;121:554-9.

18. Myers DL, Sung VW, Richter HE, et al. Prolapse symptoms in overweight and obese women before and after weight loss. Female Pelvic Med Reconstr Surg 2012;18:55-9.

19. Wasserberg N, Haney M, Petrone P, et al. Morbid obesity adversely impacts pelvic floor function in females seeking attention for weight loss surgery. Dis Colon Rectum 2007;50:2096-103.

20. Cuicchi D, Lombardi R, Cariani S, et al. Clinical and instrumental evaluation of pelvic floor disorders before and after bariatric surgery in obese women. Surg Obes Relat Dis 2013;9:69-75. 